\title{
Metabolic syndrome in family practice in Jordan: a study of high-risk groups
}

\author{
N. Yasein ${ }^{7}$ and D. Masa'd ${ }^{7}$
}

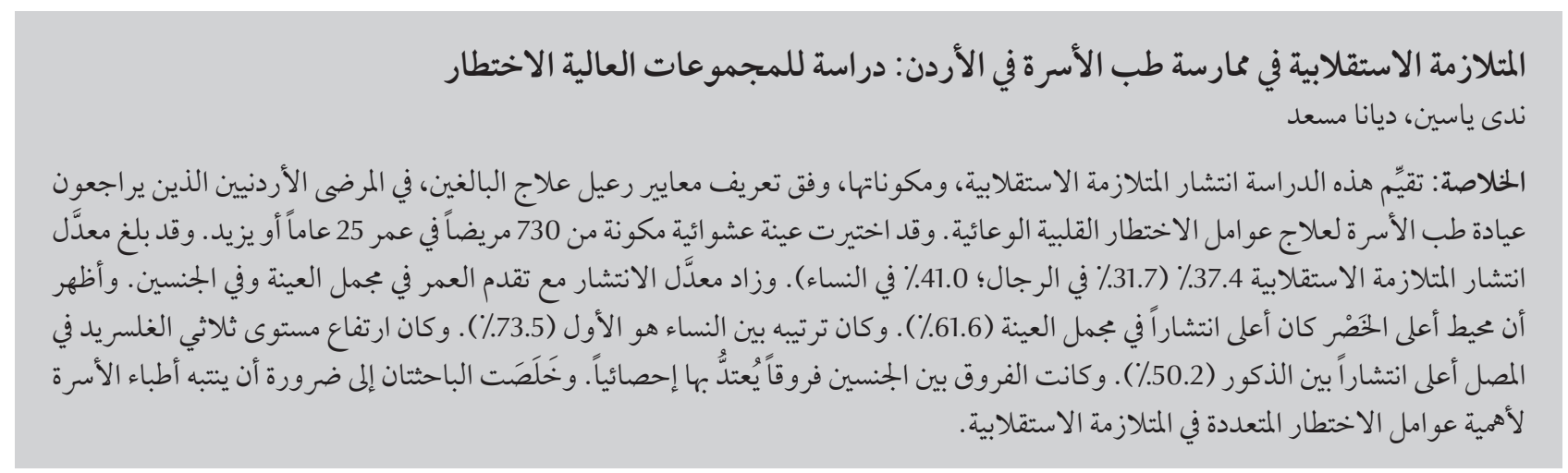

ABSTRACT This study assessed the prevalence of the metabolic syndrome, and its components, as defined by Adult Treatment Panel III criteria in Jordanian patients attending a family practice clinic for management of cardiovascular risk factors. The sample was 730 randomly selected patients aged $\geq 25$ years. The prevalence of metabolic syndrome was $37.4 \%$ (31.7\% in men; $41.0 \%$ in women). The prevalence increased with age in the total sample and in both sexes. High waist circumference showed the highest prevalence in the total sample (61.6\%). Among females it ranked as the first criterion (73.5\%). High serum triglyceride level showed the highest prevalence in males (50.2\%). Differences between the sexes were significant. Family practitioners should be alerted to the importance of multiple risk factors in the metabolic syndrome.

\section{Syndrome métabolique en médecine familiale en Jordanie : étude des groupes à haut risque}

RÉSUMÉ La présente étude a évalué la prévalence du syndrome métabolique et ses composantes selon les critères de l'Adult Treatment Panel III chez des patients jordaniens consultant dans un établissement de soins en médecine familiale pour la prise en charge des facteurs de risque cardio-vasculaires. L'échantillon comprenait 730 patients sélectionnés aléatoirement et âgés d'au moins 25 ans. La prévalence du syndrome métabolique était de 37,4 \% (31,7 \% chez les hommes ; 41,0 \% chez les femmes). Elle augmentait avec l'âge dans l'échantillon total et pour les deux sexes. Une forte prévalence d'un tour de taille élevé a été observée dans l'échantillon total (61,6 \%). Chez les femmes, cette mesure était le critère principal (73,5\%). La plus forte prévalence d'une concentration sérique en triglycérides élevée a été observée chez les hommes (50,2\%). Les différences entre les sexes étaient importantes. Les médecins de famille devraient être sensibilisés à l'importance des facteurs de risque multiples pour le syndrome métabolique. 


\section{Introduction}

The metabolic syndrome is a clustering of metabolic abnormalities which includes hyperlipidaemia [elevated triglycerides (TG), low serum high-density lipoprotein (HDL) cholesterol], hypertension, central obesity and elevated blood glucose [1]. The syndrome has been found to be associated with a greater risk of coronary heart disease, stroke and cardiovascular mortality than the risk conferred by each one of its individual components [2].

The concept of metabolic syndrome started to gain recognition several decades ago, but the ability to compare its prevalence in various populations was hindered by lack of a uniform definition of the syndrome [1]. Three definitions of the metabolic syndrome are currently in use, those of the World Health Organization in 1999 [3], the European Group for the Study of Insulin Resistance also in 1999 [4] and the National Cholesterol Education Program Expert Panel on Detection, Evaluation and Treatment of High Blood Cholesterol in Adults_-Adult Treatment Panel III (ATP III) in 2001 [5].

The ATP III definition was shown to be more useful in clinical practice since the objectives of the definition are to facilitate the diagnosis and to stress the preventive interventions related to individual components $[1,5]$. According to the ATP III guidelines demonstration of any 3 or more of the following abnormalities identifies the syndrome: waist circumference $>102 \mathrm{~cm}$ in men and $>$ $88 \mathrm{~cm}$ in women, serum TG level $\geq 150$ $\mathrm{mg} / \mathrm{dL}$, HDL-cholesterol $<40 \mathrm{mg} / \mathrm{dL}$ in men and $<50 \mathrm{mg} / \mathrm{dL}$ in women, systolic blood pressure $\geq 135 \mathrm{mmHg}$ and/ or diastolic $\geq 85 \mathrm{mmHg}$ and serum glucose level $\geq 110 \mathrm{mg} / \mathrm{dL}$. Management of the metabolic syndrome has a 2-fold objective: first, to reduce underlying causes (i.e. obesity and physical inactivity) and secondly to treat associated non-lipid and lipid risk factors [5].
Our family medicine clinic is a hospital-affiliated clinic located in Jordan University Hospital (the main teaching hospital in the capital city of Jordan, Amman), and is the primary teaching clinic for the family medicine programme. This clinic provides primary care to a socially diversified group of patients representing various population strata. Patients of this clinic are often observed to have a multitude of major cardiovascular risk factors including obesity and physical inactivity. Furthermore any data generated through this clinic is accurate, well controlled and subject to peer evaluation.

In this study we assessed the prevalence of the metabolic syndrome and its individual components as defined by ATP III in a group of patients with cardiovascular risk factors attending the family practice clinic at Jordan University Hospital. Differences in the prevalence by age and sex were also evaluated.

\section{Methods}

\section{Sample}

The sampling frame for this study was all patients aged $\geq 25$ years attending the family practice clinic at Jordan University Hospital for management and follow-up of selected cardiovascular risk factors during the study period June to December 2004.

A patient was eligible to be included in the study if he/she satisfied 1 or more of the following conditions: diagnosed as hypertensive or on medication for elevated blood pressure; diagnosed as diabetic or on treatment for diabetes mellitus; centrally obese; having family history of premature cardiovascular disease (men $<55$ years or women $\leq 65$ years); smoker; physically inactive.

Three times a week during the study period (Monday, Tuesday, Wednesday), the first 10 illegible patients attending the clinic were invited to take part in the study, an average of 30 patients per week. At the end of the 6-month study period, the number of selected patients totalled 730 (281 males and 449 females).

\section{Data collection}

Patients were oriented to the objectives of the study and their consent was secured. A special form was used for recording data on: age and sex, history of diabetes or hypertension, waist circumference, fasting lipid profile, serum TG level and serum HDL-cholesterol level. Information on smoking status, physical activity and family history of premature cardiovascular disease were also collected. Family history was considered positive if the patient reported having a first degree relative (parent, sibling or child) that has history of myocardial infarction or ischaemic stroke at age $<55$ years in men and $<65$ years in women. For the analysis, age was grouped into 4 categories $(<30,30-45$, 46-60 and > 60 years)

The ATP III criteria were used to classify patients as with or without metabolic syndrome. Subjects were considered to have metabolic syndrome if they demonstrated any 3 or more of the following abnormalities:

- Abdominal obesity: waist circumference $>102 \mathrm{~cm}$ in men and $>88 \mathrm{~cm}$ in women.

- High blood pressure: systolic blood pressure $\geq 135 \mathrm{mmHg}$ and/or diastolic $\geq 85 \mathrm{mmHg}$ or on treatment for hypertension.

- Hypertriglyceridaemia: serum TG level $\geq 150 \mathrm{mg} / \mathrm{dL}$.

- Low HDL-cholesterol: $<40 \mathrm{mg} / \mathrm{dL}$ in men and $<50 \mathrm{mg} / \mathrm{dL}$ in women.

- High fasting blood glucose: serum glucose level $\geq 110 \mathrm{mg} / \mathrm{dL}$ or on treatment for diabetes.

Blood pressure was measured in the sitting position, using a suitable cuff sphygmomanometer. Two measurements were made. Any reading above $135 / 85 \mathrm{mmHg}$ was repeated $2-3$ times over a 6-week interval. If consistent readings at this level were obtained the 
patient was labelled as hypertensive according to the ATP III definition of hypertension.

Waist circumference was measured using a steel measuring tape, with measurement made halfway between the lower border of the ribs and the iliac crest. Two measurements to the nearest $0.5 \mathrm{~cm}$ were recorded. If the variation between the measurements was greater than $2 \mathrm{~cm}$, a third measurement was taken. The mean of the 2 closest measurements was then calculated.

For the purpose of this study physical activity was defined as regular practice of any type of activity at least 3-4 times a week for duration of 20-30 minutes per session. Smoking was noted only if the subject was a current smoker.

Blood samples were taken from patient and all blood tests were done at Jordan University Hospital laboratories using an autoanalyser (Cobas Integra 400/700/800 version 1.0, Roche Laboratory Systems, Mannheim, Germany).

\section{Data analysis}

All data were entered into the computer and analysed using SPSS version 10.0. Descriptive statistics were used for the prevalence of metabolic syndrome and its components. The chi-squared test was used to examine associations between categorical variables and metabolic syndrome, its components, age, sex, smoking status and physical activity. The data were considered significant if $P \leq 0.05$.

\section{Results}

The study sample consisted of 730 subjects, 38.5\% (281) males and 61.5\% (449) females. The age ranged from 25-80 years, with a mean of 52 [standard deviation (SD 11.9)] years; males 54.9 (SD 11.9) years, females 50.0 (SD 11.7) years.

Table 1 shows the sociodemographic characteristics of the study sample: $15.9 \%$ were current smokers, $26.4 \%$ exercised regularly as defined and $11.0 \%$ had a family history of premature cardiovascular disease.

Only $9.9 \%(n=72)$ of the study sample had none of the ATP III criteria for the diagnosis of metabolic syndrome, $24.5 \%(n=179)$ had 1 abnormal criterion, $28.1 \%(n=205)$ had 2 criteria, $22.1 \%(n=161)$ had 3 criteria, $12.7 \%$ $(n=93)$ had 4 criteria and 2.7\% $(n=$ 20) had 5 criteria of the metabolic syndrome (Figure 1).

The overall prevalence of metabolic syndrome among the patients was found to be $37.4 \%$. Table 2 shows the prevalence of metabolic syndrome by sex and age groups. Sex-specific prevalence was $31.7 \%$ in men and $41.0 \%$ in women $(P<0.05)$. The prevalence generally increased with age in the total sample and in both sexes, but the trend was statistically significant in women only $(P<0.005)$. The highest prevalence was observed above 60 years of age in the total sample (48.6\%) and in both men and women $(39.1 \%$ and $57.8 \%$ respectively).
Table 3 shows the prevalence of each of the 5 ATP III criteria for diagnosis of metabolic syndrome by sex and in the total sample. The parameter with the highest prevalence was abnormal waist circumference (61.6\%), while the lowest was diabetes mellitus (21.5\%).

Among females, increased waist circumference ranked as the highest criterion followed by low serum HDL-cholesterol while high serum TG showed the highest prevalence in males and low serum HDL-cholesterol ranked second. The differences between males and females for increased waist circumference, low serum HDL-cholesterol and raised serum HDL-cholesterol were statistically significant $(P \leq 0.05)$. The differences between the sexes for the remaining criteria (hypertension and diabetes mellitus) although higher in males, did not reach statistical significance. Differences in smoking status, physical activity and family history of premature cardiovascular disease between patients with metabolic syndrome and those without were examined using the chi-squared test. Family history of premature cardiovascular disease showed a statistically significant difference $(P<$ 0.0001 ) between the 2 groups, where patients with metabolic syndrome showed an almost double prevalence of family history of premature cardiovascular disease (16.4\% versus $7.7 \%$ ). Smoking status and physical activity did not show any statistically significant difference (Table 1).

\begin{tabular}{|c|c|c|c|c|c|c|}
\hline \multirow[t]{2}{*}{ Characteristic } & \multicolumn{2}{|c|}{$\begin{array}{l}\text { With metabolic syndrome } \\
\qquad(n=274)\end{array}$} & \multicolumn{2}{|c|}{$\begin{array}{l}\text { Without metabolic } \\
\text { syndrome } \\
(n=456)\end{array}$} & \multicolumn{2}{|c|}{$\begin{array}{c}\text { Total } \\
(n=730)\end{array}$} \\
\hline & No. & $\%$ & No. & $\%$ & No. & $\%$ \\
\hline Smoking & 41 & 14.9 & 75 & 16.0 & 116 & 15.9 \\
\hline Physical activity & 65 & 23.7 & 128 & 28.0 & 193 & 26.4 \\
\hline $\begin{array}{l}\text { Family history of premature cardiovascular } \\
\text { disease }^{\mathrm{a}}\end{array}$ & 45 & 16.4 & 35 & 7.7 & 80 & 11.0 \\
\hline
\end{tabular}

${ }^{a} P<0.001$

$n=$ total number of participants. 


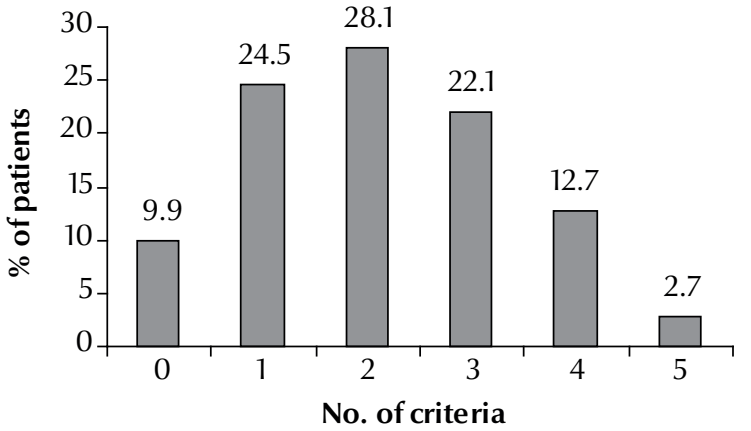

Figure 1 Distribution of the total sample of patients by number of Adult Treatment Panel III (ATP III) criteria for metabolic syndrome

\section{Discussion}

Studies estimating the prevalence of metabolic syndrome in different populations are usually not amenable to comparison [6-9]. These studies often have a variety of different study designs, sample selection, definitions of metabolic syndrome, and age and sex structure of the populations under study. Nevertheless useful inferences and comparisons can be made.

The results of our study showed a high prevalence of metabolic syndrome (37.4\% of all subjects). These findings could be due to the characteristics of the sample where $90 \%$ had at least 1 or more of the 5 abnormal components of the metabolic syndrome as defined by the ATP III criteria.

A similar study done on 250 Kuwaiti hypertensive patients attending a family medicine clinic demonstrated also a high prevalence of metabolic syndrome (34\%) [10], which is comparable to our results. In the same study, women had a higher prevalence of the syndrome than men which was also seen in our study. Other studies although with a different design also showed this sex difference [11-13].

A consistent finding in various studies is the observation that the prevalence of metabolic syndrome is highly age dependent $[1,10,14]$. The results of our study confirm this observation, as the prevalence increased with a rising age to reach a maximum above the age of 60 years for the total sample and for both sexes. It is also noted that in females the prevalence of metabolic syndrome in the age group $>60$ years was almost double that in the age group 30-45 years.

Based on clinical trials, proper and adequate management of individual components of the syndrome should prevent or delay the onset of diabetes, hypertension and cardiovascular disease [14]. Our study showed that the waist circumference as a measure of abdominal obesity ranked as the first abnormality among females and in the total sample, while elevated serum TG level ranked first among males. Even though central obesity ranked as third among males, $42.3 \%$ of them had abnormal waist circumference.

The presence of abdominal obesity was found to be highly correlated with metabolic risk factors. Therefore the simple measure of waist circumference is recommended to identify the body weight component of this syndrome. The ATP III study recognized also that some men develop multiple metabolic risk factors when waist circumference is only marginally increased [14]. Furthermore central body fat (around the body organs and in deeper tissues) was found to be associated with metabolic syndrome in older men and women whether they are of normal weight or not [15].

More than half of our study sample had low serum HDL-cholesterol levels. Similar observations were reported by studies from Oman [16] and the West Bank of Palestinian [9]. Elevated serum TG and low serum HDL-cholesterol were shown to be independent risk factors for coronary heart disease [5]. In clinical practice these 2 abnormalities are usually observed with obesity, overweight, physical inactivity, cigarette smoking and diabetes among others.

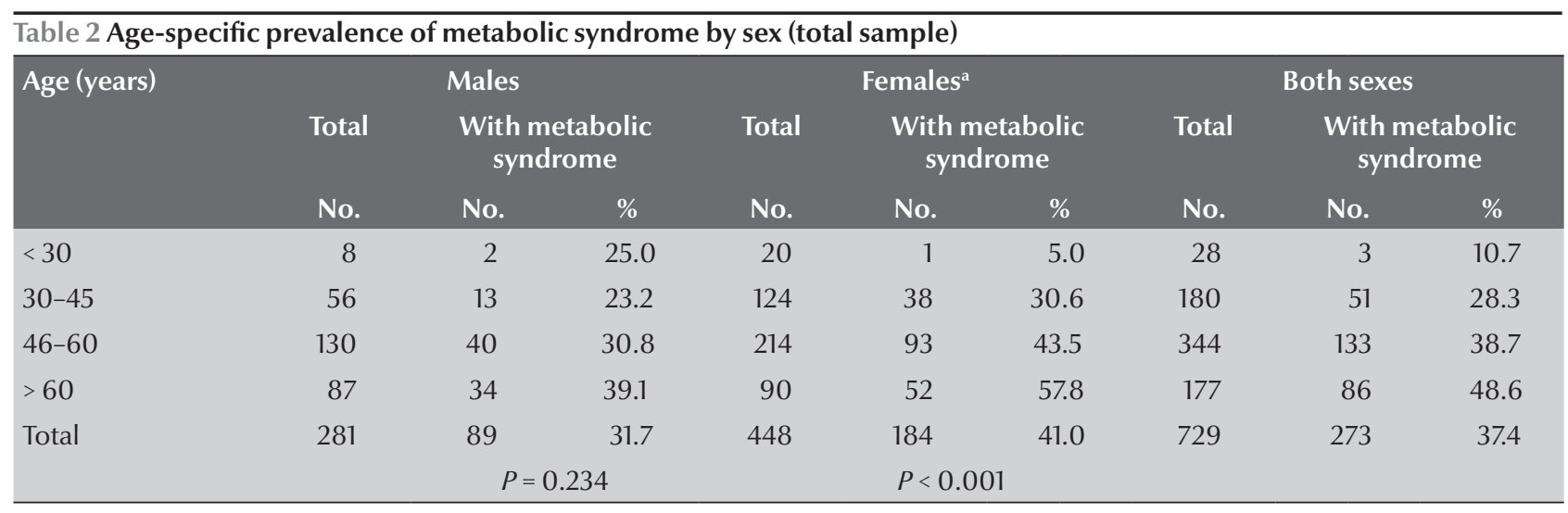




\begin{tabular}{|c|c|c|c|c|c|c|c|}
\hline \multirow[t]{2}{*}{ ATP III criteria } & \multicolumn{2}{|c|}{$\begin{array}{c}\text { Males } \\
(n=281)\end{array}$} & \multicolumn{2}{|c|}{$\begin{array}{l}\text { Females } \\
(n=449)\end{array}$} & \multicolumn{2}{|c|}{$\begin{array}{c}\text { Both sexes } \\
(n=730)\end{array}$} & \multirow[t]{2}{*}{$P$-value } \\
\hline & No. & $\%$ & No. & $\%$ & No. & $\%$ & \\
\hline Waist circumference & 119 & 42.3 & 330 & 73.5 & 449 & 61.5 & $<0.001$ \\
\hline Hypertension & 100 & 35.6 & 137 & 30.5 & 237 & 32.6 & NS \\
\hline Diabetes mellitus & 69 & 24.6 & 88 & 19.6 & 157 & 21.5 & NS \\
\hline Serum HDL-cholesterol & 130 & 46.3 & 252 & 56.1 & 382 & 52.3 & $<0.01$ \\
\hline Serum triglycerides & 141 & 50.2 & 178 & 39.6 & 319 & 43.7 & $<0.005$ \\
\hline
\end{tabular}

$H D L=$ high-density lipoprotein; $N S=$ not significant; $n=$ total number of participants.

ATP III guidelines also stress that family history of premature cardiovascular disease is considered a major risk factor that modifies the management approach of metabolic syndrome [5].

The results of this study should alert all family practitioners to the importance of multiple risk factors, as observed in the metabolic syndrome. Among men the increased risk of diabetes and cardiovascular disease are 3.7-fold and 24.5-fold for men having 4 or 5 criteria respectively compared with men having no criteria of the metabolic syndrome [17]. In women significant associations between the metabolic syndrome and subsequent 3-year risk of death or major adverse cardiovascular events has also been observed [18].

Even though the etiology of metabolicsyndrome has not been established definitely, the ATP III cites obesity and physical inactivity as the 2 underlying causes of the syndrome. This suggest that lifestyle changes and the treatment of hyperlipidaemia, diabetes and hypertension are the cornerstones for the management of metabolic syndrome.

Our study looks at metabolic syndrome in high-risk groups, and in this sense, it is the first of its kind in Jordan. However, further in-depth studies are needed to identify the syndrome not only in patients with similar conditions but also in the general Jordanian population.

\section{Acknowledgements}

The authors wish to acknowledge the valuable statistical assistance of $\mathrm{Ms}$ Luna Al-Zaro. Ms Lama Farah is deeply acknowledged for her meticulous typing and tables organization.

\section{References}

1. Cameron JA, Shaw EJ, Zimmet ZP. The metabolic syndrome: prevalence in worldwide populations. Endocrinology and Metabolism Clinics of North America, 2004, 33(2):351-375.

2. Isomaa B et al. Cardiovascular morbidity and mortality associated with the metabolic syndrome. Diabetes Care, 2001, 24:683-689.

3. Definition, diagnosis and classification of diabetes mellitus and its complications. Part 1: diagnosis and classification of diabetes mellitus. Geneva, World Health Organization, 1999.

4. Balkau B, Charles MA. Comment on the provisional report from the WHO consultation. European Group for the Study of Insulin Resistance (EGIR). Diabetic Medicine, 1999, 16:442-443.

5. Executive summary of the third report of the National Cholesterol Education Program (NCEP) Expert Panel on Detection, Evaluation, and Treatment of High Blood Cholesterol in Adults (Adult Treatment Panel III). Journal of the American Medical Association, 2001, 285:2486-2497.

6. Ramachandran A et al. Metabolic syndrome in urban Asian Indian adults: a population study using modified ATP III criteria. Diabetes Research and Clinical Practice, 2003, 60:199-204.

7. Onat A et al. Metabolic syndrome: major impact on coronary risk in a population with low cholesterol levels: a prospective and cross sectional evaluation. Atherosclerosis, 2002, 165:285-292.

8. Balkau B et al. Frequency of the WHO metabolic syndrome in European cohorts, an alternative definition of an insu- lin resistance syndrome. Diabetes and Metabolism, 2002, 28:364-376.

9. Abdul-Rahim HF et al. The metabolic syndrome in the West Bank population: an urban-rural comparison. Diabetes Care, 2001, 24:275-279.

10. Sorkhou IE et al. Prevalence of metabolic syndrome among hypertensive patients attending a primary care clinic in Kuwait. Medical Principles and Practice, 2004, 13:39-42.

11. Azizi F et al. Prevalence of metabolic syndrome in an urban population: Tehran Lipid and Glucose Study. Diabetes Research and Clinical Practice, 2003, 61:29-37.

12. Gupta A et al. Prevalence of diabetes impaired fasting glucose and insulin resistance in an urban Indian population. Diabetes Research and Clinical Practice, 2003, 61:69-76.

13. Ford ES, Giles WH, Dietz WH. Prevalence of the metabolic syndrome among U.S adults: findings from the Third National Health and Nutrition Examination Survey. Journal of the American Medical Association, 2002, 287:356-359.

14. Meigs JB. The metabolic syndrome (insulin resistance syndrome or syndrome X). UpToDate [online article] (http:// www.uptodate.com/patients/content/topic.do?print=true\&t opicKey=diabetes $/ 21989 \&$ view=print, accessed 14 November 2011).

15. Goodpaster $\mathrm{BH}$ et al. Obesity, regional body fat distribution, and the metabolic syndrome in older men and women. $\mathrm{Ar}$ chives of Internal Medicine, 2005, 165:777-783. 
16. Al-Lawati JA et al. Prevalence of the metabolic syndrome among Omani adults. Diabetes Care, 2003, 26:1781-1785.

17. Sattar $\mathrm{N}$ et al. Metabolic syndrome with and without $\mathrm{C}$-reactive protein as a predictor of coronary heart disease and diabetes in the West of Scotland Coronary Prevention Study. Circulation, 2003, 108:414-419.
18. Kip KE et al. Clinical importance of obesity versus the metabolic syndrome in cardiovascular risk in women. A report from the Women's Ischemia Syndrome Evaluation (WISE) Study. Circulation, 2004, 109:706-713.

\section{Corrections}

M. Al Adham and B. Abu Hamad. Drug dispensing systems in Gaza hospitals: a comparative study. Eastern Mediterranean Health Journal, 2011, 17(10):722-729. The Arabic abstract should read:

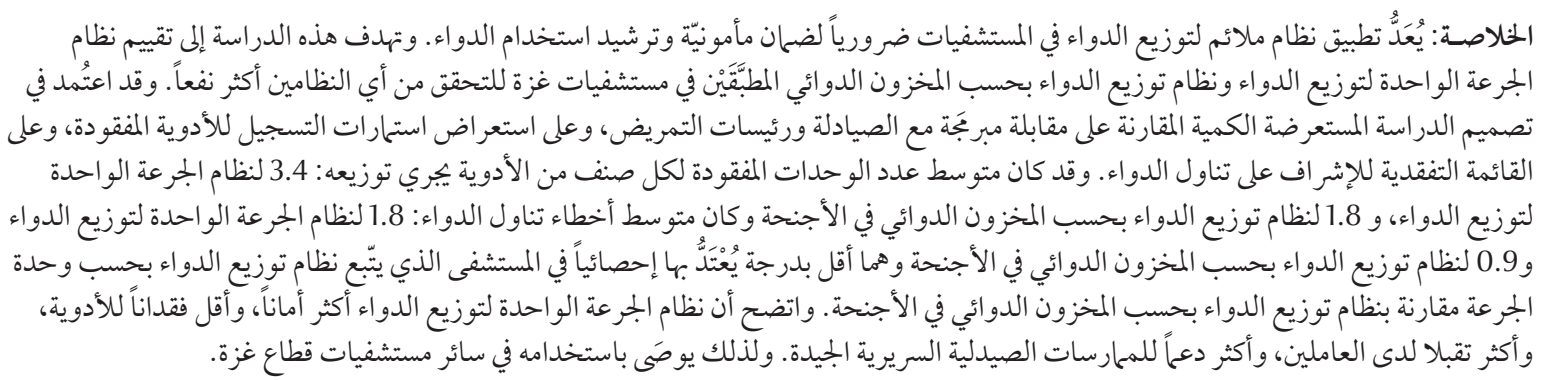

J.A. Razzak, U.R. Khan, I. Azam, M. Nasrullah, O. Pasha, M. Malik and A. Ghaffar. Health disparities between Muslim and non-Muslim countries. Eastern Mediterranean Health Journal, 201 1, 17(9):654664. The affiliation of M. Nasrullah should read: Department of Emergency Medicine, Aga Khan University, Karachi, Pakistan. 